\title{
Novos Hemilophini (Coleoptera, Cerambycidae, Lamiinae) da Coleção F. T. Hovore, Santa Clarita, California
}

\author{
Maria Helena M. Galileo ${ }^{1,3}$ \& Ubirajara R. Martins ${ }^{2,3}$ \\ ${ }^{1}$ Museu de Ciências Naturais, Fundação Zoobotânica do Rio Grande do Sul. Caixa Postal 1188, 90001-970 Porto Alegre, \\ Rio Grande do Sul, Brasil. \\ ${ }^{2}$ Museu de Zoologia, Universidade de São Paulo. Caixa Postal 42494, 04218-970 São Paulo, São Paulo, Brasil. \\ 3 Pesquisador do CNPq.
}

\begin{abstract}
New Hemilophini (Coleoptera, Cerambycidae, Lamiinae) from F. T. Hovore collection, Santa Clarita, California. New species are described: Lycidola popeba sp. nov. from Costa Rica (Limón); Hilaroleopsis pituna sp. nov. from Panamá (Chiriqui); Adesmus mosapyra sp. nov. from Ecuador (Pichincha). KEY WORDS. Adesmus; Hilaroleopsis; Lycidola; Neotropica; new species.
\end{abstract}

RESUMO. Novas espécies da tribo Hemilophini são descritas: Lycidola popeba sp. nov. da Costa Rica (Limón); Hilaroleopsis pituna sp. nov. do Panamá (Chiriqui); Adesmus mosapyra sp. nov. do Equador (Pichincha).

PALAVRAS-CHAVE. Adesmus; Hilaroleopsis; Lycidola; Neotropica; novas espécies.

Entre os Hemilophini enviados para estudo por Frank T. Hovore, Santa Clarita (FTHC) foi possível detectar novas espécies de três gêneros distintos que são descritas e comparadas com material da coleção do Museu de Zoologia, Universidade de São Paulo (MZSP).

O gênero Lycidola Thomson, 1864 foi reavaliado por Martins \& Galileo (1991) e ficou restrito a sete espécies; é reconhecido pelos antenômeros III e IV densamente pilosos; antenômero III linear, com o dobro do comprimento do escapo; élitros com quatro carenas e extremidades arredondadas.

O gênero Hilaroleopsis Lane, 1970 revisto por Martins \& GaLILEO $(1992,1997)$ foi diagnosticado pelos antenômeros basais com pêlos esparsos, pelas carenas umeral e marginal manifestas e ápice elitral arredondado e desarmado. Atualmente o gênero reúne 10 espécies (MonNé 2005).

O gênero Adesmus Lepeletier \& Audinet-Serville, 1825 foi revisto por Galileo \& Martins (1999). Novas espécies foram descritas por Martins \& Galileo (2004) e Galileo \& Martins (2005). O gênero caracteriza-se pelos élitros com carena umeral e extremidades arredondadas ou transversalmente truncadas, sem espinhos. Até o momento são conhecidas 46 espécies (Monné 2005).

\section{Lycidola popeba sp. nov.}

Fig. 1

Etimologia. Tupi, pó-peba = largo; alusivo a forma alargada dos élitros.

Cabeça alaranjada, exceto a região atrás dos olhos, preta.
Tubérculos anteníferos acastanhados. Antenas pretas, antenômeros V, VI e VII amarelados. Antenômeros III e IV densamente pilosos, o IV com pêlos mais longos e mais concentrados. Protórax alaranjado com faixa preta nos lados em toda extensão. De cada lado do pronoto uma faixa longitudinal, ligeiramente oblíqua, de pubescência esbranquiçada que vai da base ao ápice. Processos pro- e mesosternal, alaranjados. Escutelo alaranjado. Élitros alaranjados com uma faixa preta, transversal, antes do meio e o terço apical preto. Cada élitro com três carenas, manifestas. Coxas alaranjadas. Profêmures com a base alaranjada. Tíbias, tarsos e urosternitos, pretos.

Dimensões em milímetros, holótipo macho. Comprimento total, 12,9; comprimento do protórax, 1,4; maior largura do protórax, 2,2; comprimento do élitro, 10,6; largura máxima dos élitros, 7,9; largura umeral, 3,0.

Material-tipo. Holótipo macho proveniente da CosTA RicA, Limón: Rio Reventazón ("near" Siquirres), 14.III.1991, Marlin E. Rice leg., " beating forest edge" (FTHC).

Discussão. Lycidola popeba sp. nov. assemelha-se a $L$. expansa Bates, 1881 (Fig. 2) pelo padrão de colorido dos élitros e difere pela coloração da cabeça, das antenas e do protórax. A cabeça em L. popeba sp. nov. é alaranjada em sua maior parte; os antenômeros V, VI e VII são amarelados e o pronoto é alaranjado.

Em L. expansa a cabeça é preta com faixa estreita junto à sutura, de cada lado faixa mais larga, oblíqua e genas, amareladas; as antenas são inteiramente pretas ou apenas com anel basal dos flagelômeros mais claro; o pronoto é alaranjado com mancha longitudinal, central, preta. 

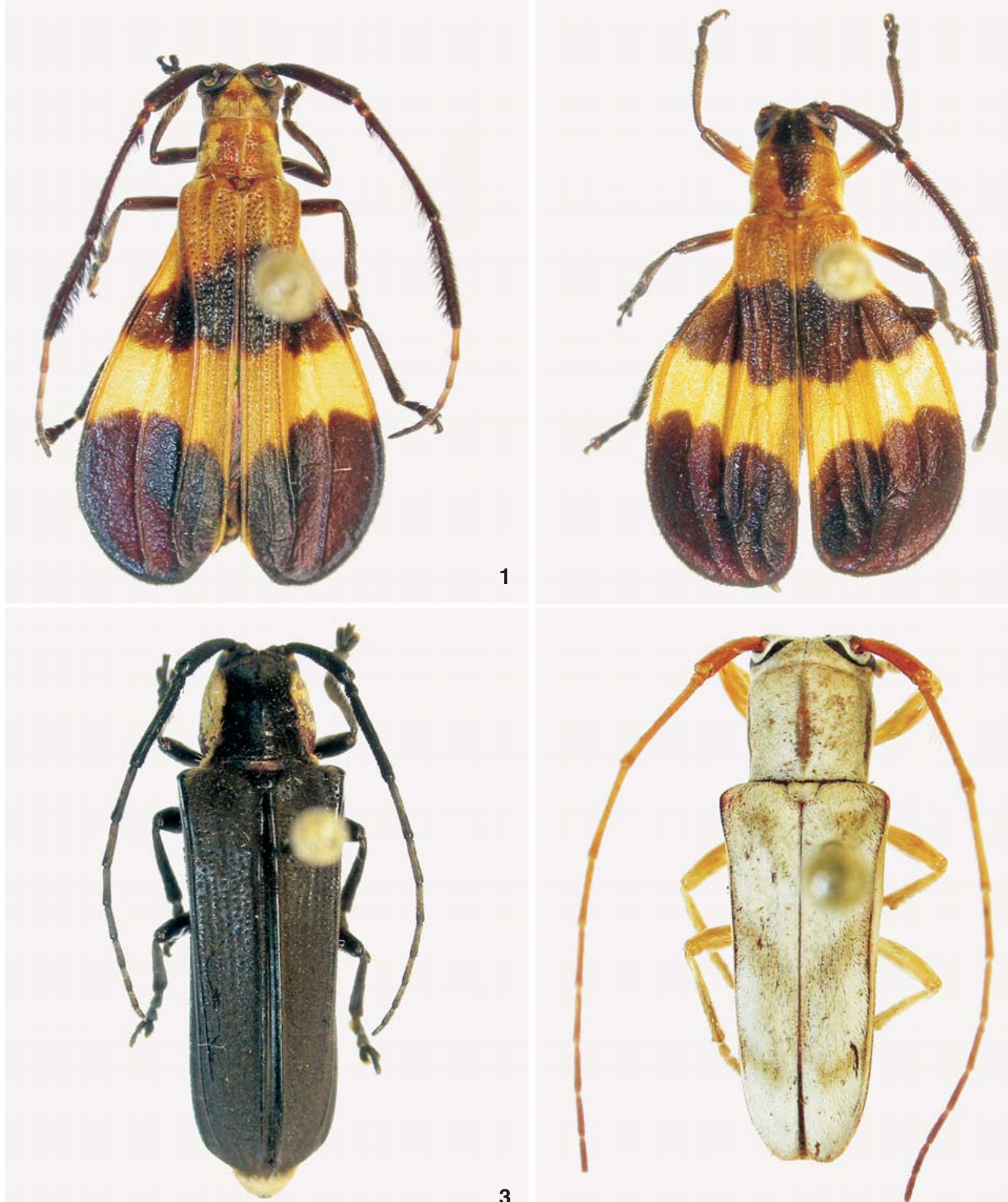

1

2
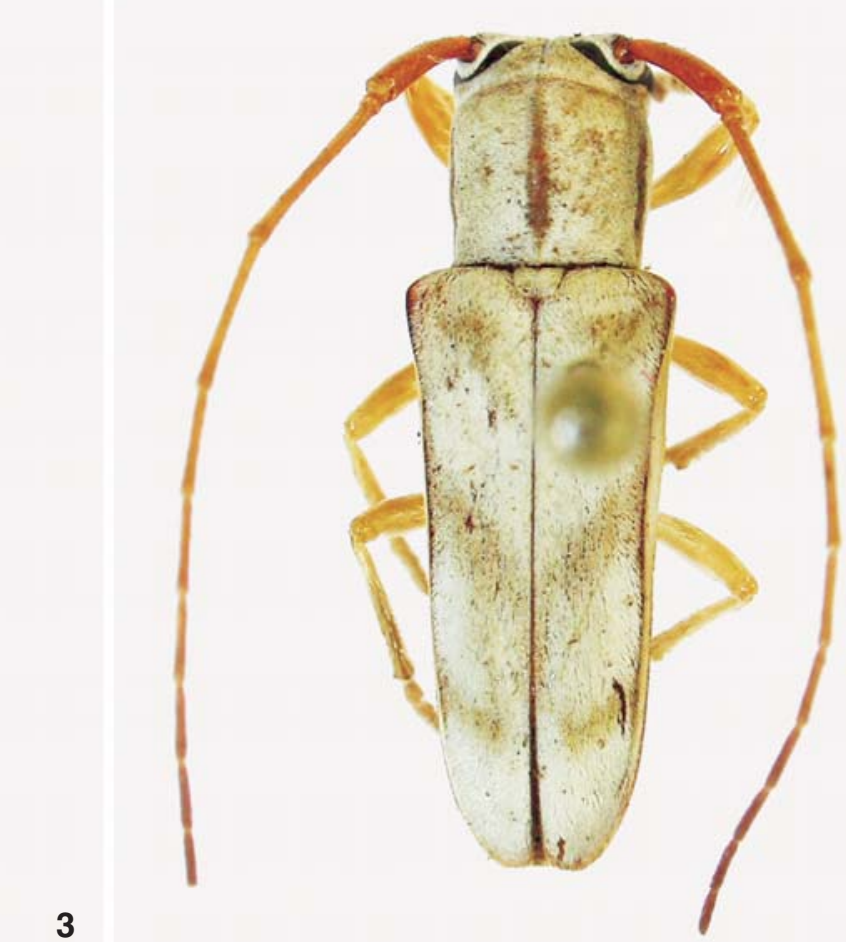

4

Figuras 1-4. (1) Lycidola popeba sp. nov., holótipo macho, comprimento 12,9 mm; (2) Lycidola expansa, macho, comprimento 12,5 mm; (3) Hilaroleopsis pituna sp. nov., holótipo fêmea, comprimento 15,2 mm; (4) Adesmus mosapyra sp. nov., holótipo macho, comprimento $10,8 \mathrm{~mm}$.

Revista Brasileira de Zoologia 23 (3): 789-791, setembro, 2006 


\section{Hilaroleopsis pituna sp. nov.}

Fig. 3

Etimologia. Tupi, pitúna $=$ noite; alusivo ao colorido corporal preto.

Colorido geral preto. Fronte (dois terços superiores), genas e regiões post-oculares com pubescência amarelo-esbranquiçada, densa, sobre tegumento castanho-avermelhado; clípeo acastanhado com a margem anterior amarelada; labro e base das mandíbulas castanho-avermelhados. Lados do protórax com larga faixa de pubescência branco-amarelada; a borda interna dessa faixa é curva. Élitros com friso sutural fortemente carenado. Parte das procoxas amarelada. Trocanteres amarelados. Articulação das tíbias com os fêmures avermelhada. Tarsômeros unicolores, pretos. Urosternitos pretos.

Dimensões em milímetros, holótipo fêmea. Comprimento total, 15,2; comprimento do protórax, 2,6; maior largura do protórax, 3,2; comprimento do élitro, 12,0; largura umeral, 4,6.

Material-tipo. Holótipo fêmea procedente do PANAMÁ, Chiriqui: Reserva Fortuna ("Continental Divide Trail"), 25.V. 1993, F. Andrews \& A. Gilbert leg. (FTHC).

Discussão. Hilaroleopsis pituna sp. nov. assemelha-se a $H$. nigerrimus (Aurivillius, 1923) conhecida da Guatemala. H. pituna sp. nov. (Fig. 3) separa-se de H. nigerrimus pela sutura coronal sem pubescência branca; pelas regiões do pronoto cobertas por pubescência branco-amarelada que não se aproximam na base do pronoto e sim estão mais distanciadas entre si; pelo friso sutural com carena elevada; pelos tarsômeros unicolores e pelos urosternitos sem pubescência branca compacta. Em H. nigerrimus (fotografia do holótipo examinada) a sutura coronal é revestida por pubescência branca; as áreas de pubescência pronotal estão mais próximas junto à base; o friso sutural não é carenado; a base dos artículos I e II dos tarsos é esbranquiçada e os urosternitos centrais são cobertos por pubescência branca, densa.

\section{Adesmus mosapyra sp. nov. Fig. 4}

Etimologia. Tupi, mosapyr = três; mosapyra = terceiro; alusivo às três faixas mais escuras nos élitros.

Tegumento castanho-avermelhado, com antenas e pernas mais claras. Todo corpo revestido por pubescência branca, menos: parte inferior da fronte, genas e gula; três faixas longitudinais, estreitas, no protórax: uma de cada lado e uma no meio do pronoto, que se aproxima, mas não toca as margens protorácicas; três faixas indistintas em cada élitro, uma oblíqua no terço basal (não atinge a sutura nem a margem), uma no meio, também oblíqua que não alcança a margem ou a sutura; uma no quarto posterior, ligeiramente oblíqua. Faixa estreita, junto às margens laterais dos élitros que envolve os ápices. A região central dos esternitos torácicos e dos urosternitos sem pubescência branca. Carena elitral curva, não atinge os ápices.

Dimensões em milímetros, holótipo macho. Comprimento total, 10,8; comprimento do protórax, 2,4; maior largura do protórax, 2,6; comprimento do élitro, 7,9; largura umeral, 3,5. Material-tipo. Holótipo macho proveniente do EquADor: Pichincha: Tinalandia (12 km E Santo Domingo de los Colorados, cerca de 2500 pés), 11-17.V.1986, J.E. Eger leg. (FTHC).

Discussão. Várias espécies de Ademus descritas por AurIviluius (1900) da Venezuela apresentam colorido semelhante: $A$. griseus, A. stephanus, A. phoebinus, A. quadricinctus entre outras. Adesmus mosapyra sp. nov. é muito semelhante a $A$. griseus e difere principalmente pela posição das faixas mais escuras dos élitros. Em A. mosapyra sp. nov. a faixa mais basal dos élitros é oblíqua e em A. griseus é inexistente (macho e fêmea) (GALILEO \& Martins, 1999: 107, figs 27, 28).

\section{AGRADECIMENTOS}

A Frank T. Hovore (FTHC) pelo envio do material para estudo; a Rafael Santos de Araújo (Museu de Ciências Naturais, Fundação Zoobotânica do Rio Grande do Sul) pela execução das fotografias.

\section{REFERÊNCIAS BIBLIOGRÁFICAS}

Auriviluius, C. 1900. Verzeichniss der von Dr. F. Meinert im Jahre 1891 in Venezuela gesammelten Cerambyciden. Öfversigt af Kongl. Svenska Vetenskaps-Akademiens Föhandlingar, Stockholm, 57: 409-421.

Galileo, M. H. M. \& U. R. Martins. 1999. O gênero Adesmus (Coleoptera, Cerambycidae, Lamiinae, Hemilophini). Iheringia, Série Zoologia, Porto Alegre, (86): 77-116.

Galileo, M. H. M. \& U. R. Martins. 2005. Contribuição aos Hemilophini da Costa Rica (Coleoptera, Cerambycidae, Lamiinae). Papéis Avulsos de Zoologia, São Paulo, 45 (10): 103-109.

Martins, U.R. \& M.H.M. GaLiLEo. 1991. Subdivisão do gênero Lycidola Thomson, 1864 (Coleoptera, Cerambycidae, Lamiinae, Hemilophini). Revista Brasileira de Entomologia, São Paulo, 35 (3): 553-565.

Martins, U.R. \& M.H.M. Galileo. 1992. O gênero Hilaroleopsis Lane, 1970 e descrições de novos táxons em Hemilophini (Coleoptera, Cerambycidae, Lamiinae). Revista Brasileira de Entomologia, São Paulo, 36 (3): 589-596.

Martins, U.R. \& M.H.M. Galileo. 1997. Remoção de espécies com duas carenas elitrais do gênero Adesmus (Coleoptera, Cerambycidae, Lamiinae, Hemilophini). Iheringia, Série Zoologia, Porto Alegre, (83): 45-64.

Martins, U.R. \& M.H.M. Galileo. 2004. Sobre Hemilophini (Coleoptera, Cerambycidae, Lamiinae) da Região Neotropical: espécies novas e novos registros. Revista Brasileira de Zoologia, Curitiba, 21 (3): 535-541.

MonNé, M.A. 2005. Catalogue of the Cerambycidae(Coleoptera) of the Neotropical region. Part II. Subfamily Lamiinae. Zootaxa, Auckland, 1023: 1-760.

Recebido em 17.I.2006; aceito em 24.VIII.2006.

Revista Brasileira de Zoologia 23 (3): 789-791, setembro, 2006 